\title{
Development of the Automobile Seat Fabric by Polyester Filament
}

\author{
Guifen Yao ${ }^{1,2, a}$ \\ ${ }^{1}$ College of Textile and Clothing Engineering, HeBei University of Science and Technology, in 70 \\ Yuhua East Road, Shijiazhuang 050018, China \\ ${ }^{2} \mathrm{HeBei}$ Textile \& Clothing Engineering Research Center, in 70 Yuhua East Road, Shijiazhuang, \\ 050018, China \\ ayaogf@hebust.edu.cn
}

\begin{abstract}
Keywords: automobile seat fabric polyester filament fabric tightness fabric weave
Abstract Automobile seat fabric is one of the decorative materials in automobile textile fabrics. The fabric should have soft handle, good air permeability, coordinate color, luxury and generous pattern, wear resistance, anti-fouling, flame retardant, certain friction factor and antistatic property. Polyester fiber is the main use raw materials for automobile seat fabric. Weaving 4 pieces of fabric with 2 kinds of different polyester filament. The fabric weave is one of plain weave, $2 / 2$ twill weave and $3 / 3$ twillweave. The physical properties of fabric, namely wear resistance, tensile strength, anti pilling, air and moisture permeability etc. are tested. Fabric tightness and fabric weave have significant affection on seat fabric properties. Increase the tightness can enhance the wear resistance, anti pilling, but will reduce the air and moisture permeability. Fabric with plain weave has better abrasion resistance and anti pilling than fabric with twill weave. Within the scope of the experimental data, the optimal scheme is the fabric with plain weave and 47 tex polyester filament yarn.
\end{abstract}

\section{Introduction}

According to statistics, more than $95 \%$ of the automobile seat use textile fabrics, only part of high-grade models with leather seats [1]. Automobile seat fabric in addition to demand the diversity of colors and designs, also requires excellent physical properties. Polyamide fiber is the earliest use raw material for automobile seat fabric. Polyester fiber is the main use raw materials for automobile seat fabric. The polyester fabric possess certain mechanical properties, such as good wear resistance, pilling resistance, aging resistance, etc., and good heat resistance, good resistance to ultraviolet radiation, good dimensional stability, good handle and comfort[2].

Automobile seat fabric inner quality refers to fiber content, fabric width deviation, square meter weight tolerance, weaves, fabric count, static dimensional change, breaking strength, wear resistance, anti pilling, air and moisture permeability, and other indicators[3].

China is the world's first automobile producer and consumer, the rapid development of automobile industry drive the development of the automobile textiles. The development direction of car seat fabric is to promote independent development and design ability.

\section{Experimental details}

\section{Raw materials}

Polyamide fiber has the best wear resistance. But the use of polyamide fiber is limited for its poor ultraviolet radiation resistance. The cellulosic fiber use on automobile seat fabric is fewer than that of synthetic fiber, because the cellulosic fiber such as cotton and viscose rayon has lower abrasion resistance and anti-wrinkle performance.

Polyester fiber is the main use raw materials for automobile seat fabric. Application of the polyester fabric accounts for about $90 \%$. Polyester fiber has high strength and modulus, good resistance to heat and ultraviolet radiation, excellent anti-aging performance, good shape and dimension stability.

Using 47tex and 113tex polyester filament weave the fabric for automobile seat. The tensile properties of the polyester filament is shown in table 1. 
Table 1 The tensile properties of the polyester filament

\begin{tabular}{|c|c|c|c|c|}
\hline $\begin{array}{c}\text { Yarn Fineness } \\
{[\text { tex] }}\end{array}$ & $\begin{array}{c}\text { Tensile strength } \\
{[\mathrm{cN} / \text { tex] }}\end{array}$ & $\begin{array}{c}\text { Tensile strength } \\
\text { irregularity[\%] }\end{array}$ & $\begin{array}{c}\text { Tensile } \\
\text { elongation[\%] }\end{array}$ & $\begin{array}{c}\text { Tensile elongation } \\
\text { irregularity [\%] }\end{array}$ \\
\hline 47 & 67.1 & 1.9 & 20.6 & 3.1 \\
\hline 113 & 79.9 & 2.4 & 14.0 & 2.7 \\
\hline
\end{tabular}

\section{Fabric characteristics}

The woven automobile seat fabrics are plain weave, $2 / 2$ twill weave, and $3 / 3$ twill weave polyester filament fabrics. The yarns are 47 tex and 113 tex polyester filament yarns. The fabric is woven on the Y200S little loom. The fabric specifications is shown in table 2.

Table 2 The fabric specifications

\begin{tabular}{|c|c|c|c|c|}
\hline $\begin{array}{c}\text { Fabric } \\
\text { number }\end{array}$ & $\begin{array}{c}\text { Yarn } \\
\text { fineness[tex] }\end{array}$ & $\begin{array}{c}\text { Warp } \\
\text { density[/10cm] }\end{array}$ & $\begin{array}{c}\text { Weft } \\
\text { density[/10cm }]\end{array}$ & Fabric weave \\
\hline 1 & 113 & 160 & 110 & Plain weave \\
\hline 2 & 113 & 170 & 160 & $3 / 3$ Twill weave \\
\hline 3 & 47 & 190 & 220 & Plain weave \\
\hline 4 & 113 & 160 & 150 & $2 / 2$ Twill weave \\
\hline
\end{tabular}

\section{Fabric tightness}

The fabric tightness refers to the percentage of yarn projection area and fabric area, nature is the coverage coefficient of yarn. Can calculate warp tightness $E_{T}$ with equation (1), weft tightness $E_{W}$ with equation (2) and total tightness $E_{Z}$ with equation (3). The fabric tightness has a influence on the fabric performance, such as fabric density, handle, fastness, and permeability. Fabric tightness is one of the important content of textile design. Equation (1) to (3) is shown as follows.

$$
\begin{aligned}
& E_{T}=0.03568 \sqrt{\frac{N_{t}}{\delta_{y}}} \cdot P_{T} \\
& E_{W}=0.03568 \sqrt{\frac{N_{t}}{\delta_{y}}} \cdot P_{W} \\
& E_{Z}=E_{T}+E_{W}-E_{T} \cdot E_{W} / 100
\end{aligned}
$$

$\delta_{y}$ : the yarn density $\left(\mathrm{g} / \mathrm{cm}^{3}\right) ; N_{t}$ : the yarn number (tex); $P_{T}$ : warp density $(/ 10 \mathrm{~cm}) ; P_{W}$ : weft density $(/ 10 \mathrm{~cm})$.

According to the formula (1) to (3), the fabric warp tightness $\mathrm{E}_{\mathrm{T}}$, weft tightness $\mathrm{E}_{\mathrm{W}}$ and total tightness EZ is calculated. The fabric tightness is shown in table 3.

Can be seen from the table 3, fabric with twill weave has the largest fabric tightness. Fabric tightness is positively related to yarn diameter and yarn density.

Table 3 The fabric tightness

\begin{tabular}{|c|c|c|c|c|}
\hline Fabric number & Yarn diameter[mm] & $\mathrm{E}_{\mathrm{T}}$ & $\mathrm{E}_{\mathrm{W}}$ & $\mathrm{E}_{\mathrm{Z}}$ \\
\hline 1 & 0.323 & 51.7 & 35.5 & 68.8 \\
\hline 2 & 0.323 & 54.9 & 51.7 & 78.2 \\
\hline 3 & 0.208 & 39.5 & 45.8 & 67.2 \\
\hline 4 & 0.323 & 51.7 & 48.5 & 75.1 \\
\hline
\end{tabular}

\section{Determination of fabric propensity for fuzzing and pilling}

Circular locus method was the most commonly used determination method of fabric propensity for fuzzing and pilling. The basic principle of the circular locus method is: make the fabric sample under 
certain pressure along the circular motion, with nylon brush fuzzing, then with fabric abrasive for relative friction pilling [4]. Visual description ratings is divided into five grade, grade from 1 to 5, 1 grade worst, 5 grade best, allow half grade.

Choose experimental parameters are as follows:

Pressure: $490 \mathrm{cN}$; fuzzing number: 50; pilling number: 50; Circular movement speed: $60 \mathrm{r} / \mathrm{min}$.

\section{Determination of fabric abrasion resistance}

Determination of the abrasion resistance of fabrics by Martindale method. Friction load: $(795 \pm 7) \mathrm{g}$. Under a certain number of friction, measure mass loss, then get the abrasion index(times/mg)[5].

\section{Determination of fabric air permeability rate}

According to GB/T 5453 Textiles-Determination of the permeability of fabrics to air, use the YG(B)461D/II type digital fabric air permeability instrument for the air permeability test. The experimental parameters are: test area is $20 \mathrm{~cm}^{2}$; nozzle number is 4 ; initial ventilation rate is 20 $\mathrm{mm} / \mathrm{s}$; differential pressure of sample is set to $100 \mathrm{~Pa}$. Press the start button and instrument start testing automatically, when to set pressure difference on both ends of the specimen, record air flow [6].

\section{Determination of fabric moisture permeability}

According to GB/T 12704.1-2009 Textiles - Test method for water-vapour transmission of fabrics - Part 1: Desiccant method. Cut the sample into a diameter of $80 \mathrm{~mm}$ circle. Test conditions: temperature $38{ }^{\circ} \mathrm{C}$, relative humidity $90 \%$.

Moisture vapor transmission cup load $35 \mathrm{~g}$ desiccant, desiccant dry in $160{ }^{\circ} \mathrm{C}$ oven $3 \mathrm{~h}$. Place the sample testing face up on the moisture permeability cup, install pressure ring, screw nut, form the test assembly. The test assembly will be placed in the specified test conditions for $60 \mathrm{~min}$. Take out the test assembly, cover the lid. Balance in $20{ }^{\circ} \mathrm{C}$ silica gel dryer for $30 \mathrm{~min}$, weighing, accurate to 0.001 g. Remove lid and place the test assembly in the specified test conditions for $60 \mathrm{~min}$, balance and weighing, accurate to $0.001 \mathrm{~g}$ [7].

\section{Determination of fabric tensile properties}

According to the national standard GB/T 3923.1 textile-tensile properties of fabric-Part 1: determination of maximum force and elongation at maximum force using the strip method[8]. Choose UTM5150 electronic universal testing machine to test the fabric maximum force and elongation at maximum force.

\section{Results and discussion}

According to relevant standard, test the automobile seat fabric physical indexes, such as anti-pilling, abrasion resistance, air permeability, moisture permeability, warp breaking strength and weft breaking strength. Test results is shown in table 4 .

As shown in table 4, the difference of abrasion index and air permeability is obvious.

Table 4 The fabric properties

\begin{tabular}{|c|c|c|c|c|c|c|}
\hline $\begin{array}{c}\text { Fabric } \\
\text { number }\end{array}$ & $\begin{array}{c}\text { Pilling } \\
\text { [grade] }\end{array}$ & $\begin{array}{c}\text { Abrasion } \\
\text { index } \\
\text { [times } / \mathrm{mg}]\end{array}$ & $\begin{array}{c}\text { Air } \\
\text { permeabilit } \\
\mathrm{y}[\mathrm{mm} / \mathrm{s}]\end{array}$ & $\begin{array}{c}\text { Moisture } \\
\text { permeabilit } \\
\left.\mathrm{y} / \mathrm{g} /\left(\mathrm{m}^{2} \cdot \mathrm{h}\right)\right]\end{array}$ & $\begin{array}{c}\text { Warp } \\
\text { breaking } \\
\text { strength[N] }]\end{array}$ & $\begin{array}{c}\text { Weft } \\
\text { breaking } \\
\text { strength[N] }\end{array}$ \\
\hline 1 & 4.5 & 22.1 & 57.4 & 20.8 & 1824 & 1270 \\
\hline 2 & 4 & 3.3 & 318.4 & 24.7 & 1472 & 1181 \\
\hline 3 & 5 & 52.0 & 72.6 & 22.1 & 1010 & 1385 \\
\hline 4 & 4.5 & 8.0 & 253.6 & 23.7 & 1643 & 1202 \\
\hline
\end{tabular}




\section{The influence factors of abrasion index}

Fabric 2 and fabric 4 with twill weave has low abrasion index, fabric 1 and fabric 3 with plain weave has high abrasion index. The fabric weave has significant affection on fabric abrasion index. Twill weave fabric has long floating. The fabric is soft. Yarn cohesive force is small, abrasion index is low. Abrasion index is negatively related to floating. The fabric with plain weave accord with the requirement of automobile seat fabric in abrasion index.

Fabric 3 has the highest abrasion index among the four fabric. The yarn fineness and yarn density have significant affection on abrasion index.

The influence factors of abrasion index include yarn fineness and fabric weave.

\section{The influence factors of air permeability}

Fabric 2 and fabric 4 with twill weave has high air permeability, fabric 1 and fabric 3 with plain weave has low air permeability. Twill weave fabric is breathable, because twill weave has long floating. The fabric is soft. Yarn cohesive force is small, air through easily. Air permeability is positively related to floating. The fabric with twill weave accord with the requirement of automobile seat fabric in air permeability.

Fabric 1 has lower air permeability than fabric 3. Air permeability is negatively related to fabric tightness.

The influence factors of air permeability include fabric tightness and fabric weave. Fabric tightness is determined by yarn fineness and yarn density.

\section{Conclusions}

From what has been discussed above, in the process of automobile seat fabric design, material selection and fabric structure design have a decisive influence on the performance of the result fabric.

Within the scope of the experimental data, fabric weave and fabric tightness have significant effect on fabric property.

Increase the tightness can enhance the wear resistance, anti pilling, but will reduce the air and moisture permeability.

Fabric with plain weave has better abrasion resistance and anti pilling than fabric with twill weave. Fabric with plain weave accord with the requirement in abrasion index and anti pilling.

In conclusion, the optimal scheme for automobile seat fabric design is the woven fabric with plain weave and 47 tex polyester filament yarn.

\section{References}

[1] Liu li, Maolei. Introduction to automobile textile material selection and basis[J]. Shandong textile economy, 2009 (4) : 108-20

[2] Wu Xiangji, Xin Binjie. Application analysis of automotive seat fabric[J]. Journal of industrial textiles, $2013(2): 38$ and 39

[3] Xu Zhenzhen, etc., Research on Flame Retardant and Fouling Resistance Finishing of New Type Automobile Seat Fabric. Journal of Huainan Vocational and Technical College, 2011 (3), 80-81

[4] GB/T 4802.1-2008 Textiles - Determination of fabric propensity for fuzzing and pilling - Part 1 : Circular locus method

[5] GB/T 21196.3-2007 Textiles - Determination of the abrasion resistance of fabrics by the Martindale method - Part 3: Determination of mass loss

[6] GB/T 5453-1997 Textiles-Determination of the permeability of fabrics to air

[7] GB/T 12704.1-2009 Textiles - Test method for water-vapour transmission of fabrics - Part 1: Desiccant method

[8] GB/T 3923.1-2013 Textile-tensile properties of fabric-Part 1: determination of maximum force and elongation at maximum force using the strip method 